\title{
The effect of posterior sub-Tenon's capsule triamcinolone acetonide injection to that of pars plana vitrectomy for diabetic macular edema
}

This article was published in the following Dove Press journal:

Clinical Ophthalmology

30 April 2014

Number of times this article has been viewed

\section{Sakiko Nonomura \\ Toshiyuki Oshitari \\ Miyuki Arai \\ Eiju Sato \\ Yoko Takatsuna \\ Takayuki Baba \\ Shuichi Yamamoto}

Department of Ophthalmology and Visual Science, Chiba University Graduate School of Medicine,

Chiba, Japan
Correspondence:Toshiyuki Oshitari Department of Ophthalmology and Visual Science, Chiba University Graduate School of Medicine, Inohana I-8-I, Chuo-ku, Chiba 260-8670, Chiba, Japan

$\mathrm{Tel}+81432262124$

Fax +8I 432244162

Email tarii@aol.com
Purpose: To compare the effect of posterior sub-Tenon's capsule triamcinolone acetonide (STTA) injection to that of pars plana vitrectomy (PPV) for diabetic macular edema (DME).

Patients and methods: The medical records of 50 patients (52 eyes) with DME were reviewed. Twenty-six eyes underwent STTA $(20 \mathrm{mg})$ and the other 26 eyes underwent vitrectomy combined with cataract surgery. The central macular thickness (CMT), measured by optical coherence tomography, and best-corrected visual acuity (BCVA) were determined before and 1, 3, and 6 months after treatment.

Results: The differences in the BCVA and the CMT between the STTA group and the PPV group were not significant before or at any time after the treatment. In both the STTA and PPV groups, there were significant differences between the pre-treatment CMT and BCVA at any time after treatment.

Conclusion: We recommend STTA injection for the treatment of DME.

Keywords: diabetic macular edema, posterior sub-Tenon's capsule triamcinolone acetonide injection, pars plana vitrectomy, central macular thickness

\section{Introduction}

Diabetic macular edema (DME) is one of the major causes of visual acuity decrease in diabetic patients at all stages of diabetic retinopathy (DR). ${ }^{1}$ Several treatments for DME have been used, eg, grid laser photocoagulation, ${ }^{2}$ intravitreal injection of triamcinolone acetonide (IVTA), ${ }^{3}$ posterior sub-Tenon's capsule triamcinolone acetonide (STTA) injection, ${ }^{4}$ pars plana vitrectomy (PPV), subthreshold micropulse diode laser photocoagulation, ${ }^{5}$ and intravitreal injection of anti-vascular endothelial growth factor (VEGF) drugs. ${ }^{6-9}$ However, the most effective treatment for DME has not been determined.

There have been studies comparing the effectiveness of IVTA to PPV, ${ }^{10}$ and IVTA to STTA injection, ${ }^{11}$ however a PubMed search did not extract any studies comparing the effectiveness of PPV to STTA injection. Thus, the purpose of this study was to compare the effectiveness of STTA injection to that of PPV in eyes with DME.

\section{Patients and methods}

The medical records of 52 eyes of 50 patients with DME who were examined in Chiba University Hospital between January 1, 2010 and December 31, 2010 were reviewed. Twenty-six eyes of 26 patients had $20 \mathrm{mg}$ of triamcinolone acetonide (TA) injected 
into the sub-Tenon space alone. Five of these eyes were pseudophakic. Three eyes underwent STTA twice during the follow-up period. The outcomes of these 26 eyes that underwent STTA were compared to 26 naïve eyes of 24 patients who underwent 20-gauge or 23-gauge vitrectomy combined with cataract surgery between January 1, 2009 and December 31, 2010. Any remaining vitreous and posterior vitreous membrane was meticulously removed by using TA to visualize the vitreous. In addition, the peeling of the internal limiting membrane was performed in accordance with the operator's decision. Five eyes were pseudophakic and underwent vitrectomy only. The remaining 21 eyes had mild to moderate cataracts. Vitrectomy was considered only if the patients agreed to the surgical treatments. The specific indication of vitrectomy for DME was not determined in our hospital but the patients without posterior vitreous detachment were usually recommended. Although the specific indication of STTA for DME was not determined, if the patients did not agree to vitrectomy, STTA was considered. However, vitrectomy and STTA were usually recommended for the patients with slightly thicker fovea than the patients treated with micropulse diode laser photocoagulation in our previous study. ${ }^{5}$

After a complete explanation of the procedures to be performed, a signed informed consent was obtained from all patients. All of the procedures conformed to the tenets of the World Medical Association Declaration of Helsinki. Approval for this study was obtained from the Institutional Review Board of Chiba University Hospital, Japan.
The central macular thickness (CMT) was measured by spectral domain-optical coherence tomography (SD-OCT) before and 1, 3, and 6 months after the procedures. The best-corrected visual acuity (BCVA) was measured at the same times.

The data are expressed as the means \pm standard deviations (SDs). The significance of differences was determined by Student's $t$-tests, paired $t$-tests, chi-square tests, and repeated measured analysis of variance (ANOVA). A $P<0.05$ was considered significant.

\section{Results}

The clinical information and features of all the participants are shown in Table 1. No significant differences were detected in age, sex, glycated hemoglobin $\left(\mathrm{HbA}_{1 \mathrm{c}}\right)$, numbers of pseudophakic eyes, preoperative BCVA, and preoperative OCT between the PPV and STTA groups. In the PPV group, however, 21 eyes underwent pan retinal photocoagulation (PRP) which was significantly different from the 12 eyes that underwent PRP in the STTA group. DR stages of the remaining eyes in both groups were of non-proliferative DR. The significance of differences in age, $\mathrm{HbA}_{1 \mathrm{c}}, \mathrm{BCVA}$, and CMT were determined by Student's $t$-tests. Other significant differences were determined by chi-square test. The preoperative BCVA was $0.65 \pm 0.4$ logarithm of the minimum angle of resolution (logMAR) units in the STTA group and $0.77 \pm 0.3$ logMAR units in the PPV group ( $P=0.237$; Student's $t$-test; Figures 1 and 2). At 1, 3, and 6 months, the BCVAs in

Table I Clinical data and features

\begin{tabular}{|c|c|c|c|}
\hline & PPV & STTA & $P$-values \\
\hline Age (years; mean $\pm S D)$ & $62.65 \pm 1.55$ & $61.92 \pm 2.27$ & $P=0.793$ \\
\hline \multicolumn{4}{|l|}{ Sex } \\
\hline Men & 12 & 16 & \multirow[t]{2}{*}{$P=0.404$} \\
\hline Women & 14 & 10 & \\
\hline \multicolumn{4}{|l|}{ Type of diabetes } \\
\hline Type I & 0 & I & \multirow[t]{2}{*}{$P>0.999$} \\
\hline Type 2 & 26 & 25 & \\
\hline $\mathrm{HbA}_{\mathrm{Ic}}(\% ;$ mean $\pm \mathrm{SD})$ & $6.52 \pm 0.19$ & $6.7 \pm 1.0$ & $P=0.31 \mathrm{I}$ \\
\hline \multicolumn{4}{|l|}{ Treatment of diabetes } \\
\hline Oral treatment & 8 & 14 & $P=0.161$ \\
\hline Insulin & 18 & 3 & $P<0.0001$ \\
\hline Diabetic nephropathy & 13 & 10 & $P=0.577$ \\
\hline PRP & 21 & 12 & $P=0.0089$ \\
\hline Pseudophakic eyes & 5 & 5 & $P>0.999$ \\
\hline BCVA (logMAR; mean \pm SD) & $0.77 \pm 0.31$ & $0.57 \pm 0.43$ & $P=0.237$ \\
\hline $\mathrm{CMT}(\mu \mathrm{m} ;$ mean $\pm \mathrm{SD})$ & $534 \pm 157$ & $551 \pm 167$ & $P=0.444$ \\
\hline $\mathrm{IOP}(\mathrm{mmHg} ;$ mean $\pm \mathrm{SD})$ before treatment & $16.04 \pm 16.04$ & $|4.39 \pm 7.2|$ & $P=0.0557$ \\
\hline $\mathrm{IOP}(\mathrm{mmHg}$; mean $\pm \mathrm{SD}) 6$ months after treatment & $15.13 \pm 14.66$ & $16.78 \pm 8.18$ & $P=0.1787$ \\
\hline
\end{tabular}

Abbreviations: PPV, pars plana vitrectomy; STTA, sub-Tenon's capsule triamcinolone acetonide; CMT, central macular thickness; HbA ${ }_{1 \mathrm{c}}$ glycated hemoglobin; PRP, pan retinal photocoagulation; BCVA, best-corrected visual acuity; IOP, intraocular pressure; SD, standard deviation. 
A PPV 48 years, male

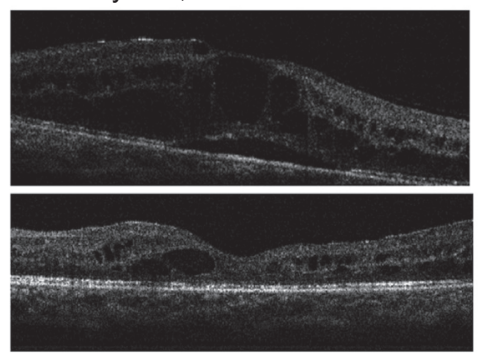

Before treatment

VA $0.4 \log M A R$

CMT $709 \mu \mathrm{m}$

6 months after treatment

VA 0.5 logMAR

CMT $217 \mu \mathrm{m}$

B STTA 69 years, male

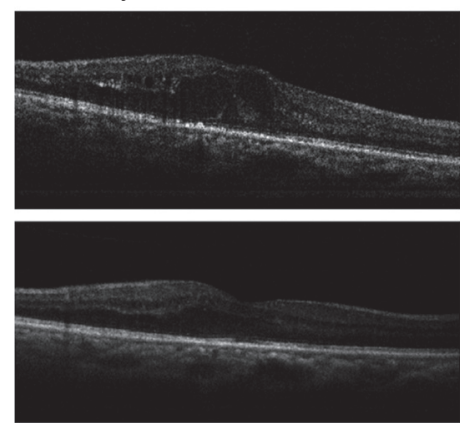

Before treatment

VA $0.5 \log M A R$

CMT $578 \mu \mathrm{m}$

6 months after treatment

VA $0.4 \log M A R$

CMT $382 \mu \mathrm{m}$

Figure I Representative cases of DME treated with PPV or STTA.

Notes: (A) Representative case of a 49-year-old man who underwent PPV for DME. After the PPV treatment, the DME showed significant improvement. (B) Representative case of a 69-year-old man who was treated with STTA. After STTA treatment, DME showed significant improvement.

Abbreviations: PPV, pars plana vitrectomy; DME, diabetic macular edema; STTA, sub-Tenon's capsule triamcinolone acetonide; logMAR, logarithm of the minimum angle of resolution; CMT, central macular thickness; VA, visual acuity.

$\log$ MAR units were $0.60 \pm 0.4,0.59 \pm 0.5$, and $0.64 \pm 0.5$ respectively, in the STTA group and $0.68 \pm 0.4,0.59 \pm 0.4$, and $0.59 \pm 0.4$ respectively in the PPV group (Figures 1 and 2). The differences in the BCVA between the two groups were not significant before and at any time after treatment $(P=0.441$, $P=0.960, P=0.717$; Student's $t$-tests and $P=0.5477$ by repeated measured ANOVA). In the STTA group, there were no significant differences between the pre-treatment BCVA and that at any time after the STTA $(P=0.226, P=0.340$, $P=0.775$; paired $t$-tests). In the PPV group, there was no significant difference between the pre-treatment BCVA and that at 1 month after PPV, but there were significant differences between the pre-treatment BCVA and that at 3 and 6 months after PPV $(P=0.389, P=0.0066, P=0.0169$ respectively; paired $t$-tests).

The preoperative CMT was $569.2 \pm 167 \mu \mathrm{m}$ in the STTA group and $534.4 \pm 157 \mu \mathrm{m}$ in the PPV group (Figure 3). At 1,3 , and 6 months, the CMT was $356.1 \pm 116 \mu \mathrm{m}$, $326.7 \pm 111.7 \mu \mathrm{m}$, and $377.4 \pm 137.6 \mu \mathrm{m}$, respectively in the STTA group, and $386.8 \pm 175 \mu \mathrm{m}, 354.2 \pm 101.7 \mu \mathrm{m}$ and $354.2 \pm 156.4 \mu \mathrm{m}$, respectively in the PPV group (Figure 3). The differences in the CMT between the two groups were not significant before and at any time after
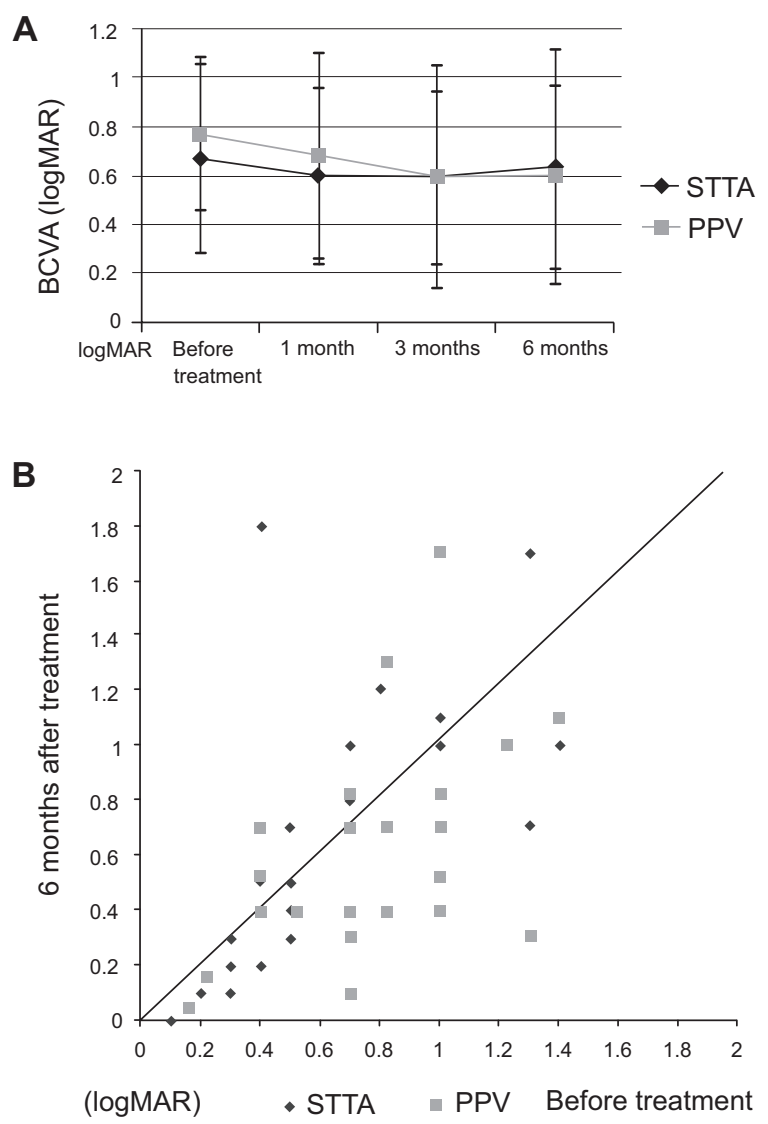

Figure 2 Changes of BCVA as a function of postoperative time (A) and BCVA before (abscissa) and after (ordinate) treatment (B).

Notes: In the STTA group, there were no significant differences between the pretreatment BCVA and that at I, 3, and 6 months after the treatment. In the PPV group, there were significant differences between the pre-treatment BCVA and that at 3 and 6 months after PPV $(P=0.0066, P=0.0169$, respectively). There was no significant difference at each period between PPV and STTA group.

Abbreviations: BCVA, best-corrected visual acuity; STTA, sub-Tenon's capsule triamcinolone acetonide; PPV, pars plana vitrectomy; logMAR, logarithm of the minimum angle of resolution.

the PPV $(P=0.444, P=0.460, P=0.469, P=0.273$ respectively by Student's $t$-tests and $P=0.2053$ by repeated measured ANOVA). In both the STTA and PPV groups, there were significant differences between the pre-treatment CMT and that at 1,3 , and 6 months after treatment (STTA; $P<0.0001$, $P<0.0001, P=0.0001$ respectively by paired $t$-tests, PPV; $P=0.0013, P<0.0001, P<0.0001$ respectively by paired $t$-tests).

Three eyes in the STTA group had a temporary increase in the intraocular pressure (IOP), and topical anti-glaucoma drugs controlled the IOP during this period. One eye in the PPV group had a temporary increase in IOP, another eye developed wound infection but not endophthalmitis.

\section{Discussion}

Doi et al reported that IVTA in eyes with DME significantly reduced the CMT, and the CMT was not significantly 

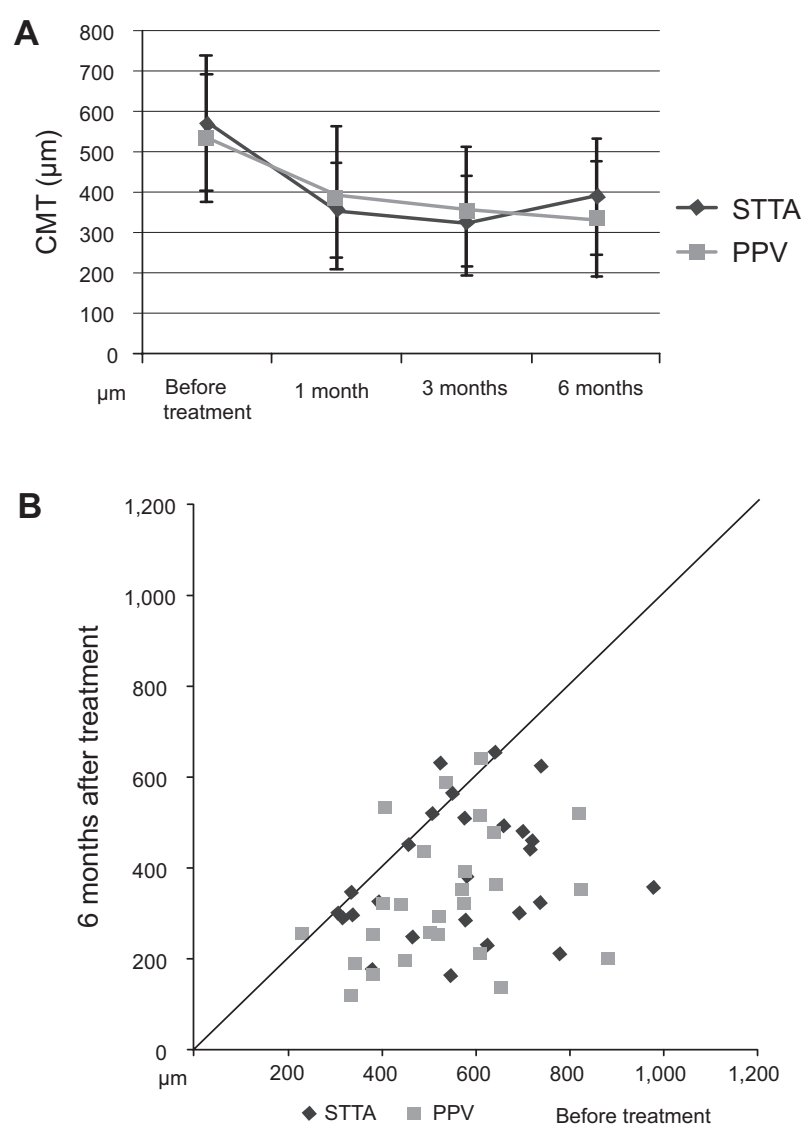

Figure 3 Changes of CMT as a function of postoperative time (A) and the CMT before and after treatment (B) at 6 months.

Notes: In both the STTA and PPV groups, there were significant differences in the CMT between the pre-treatment and that at I, 3, and 6 months after treatment (STTA; $P<0.000 \mathrm{I}, P<0.000 \mathrm{I}, P=0.000 \mathrm{I}$, respectively, PPV; $P=0.0013, P<0.000 \mathrm{I}$, $P<0.000$ I, respectively). There was no significant difference at each time between PPV and STTA group.

Abbreviations: CMT, central macular thickness; STTA, sub-Tenon's capsule triamcinolone acetonide; PPV, pars plana vitrectomy.

different from that in the PPV group at 3 months after the treatment. ${ }^{10}$ The results of their study are in accordance with our results. However, the DME recurred 6 months after IVTA in their study while it remained resolved after PPV. ${ }^{10}$ In this study, three eyes were retreated with STTA 3-6 months after the first treatment. Thus, repeated treatment of IVTA or STTA may be considered 3-6 months after steroid-based treatment for refractory DME.

Qi et al reported that within 3 months, IVTA is more effective than STTA in improving VA and reducing CMT in patients with refractory DME. However, the benefits of either regimen were no longer evident at 6 months. ${ }^{11}$ Taken together, our results indicate that although repeated injections may be required, the effect of STTA is not inferior to that of IVTA or PPV in the short term.

Hoerauf et al studied 50 patients who had undergone PPV for DME and reported that iatrogenic tears developed intraoperatively in ten patients, cataracts developed within 6 months in 42/44 (95.45\%) phakic eyes, a dense postoperative vitreous hemorrhage requiring a second vitrectomy with silicone oil tamponade developed in one patient, and a retinal detachment developed in three eyes which required a second vitrectomy. ${ }^{12}$ Because a cataract is highly complicated after PPV, we routinely combined cataract surgery with PPV for DME patients with phakic eyes. In the PPV group, 21 eyes had mild to moderate cataract and underwent cataract removal simultaneously during PPV. The cataract removal may contribute to the improvement of BCVA in the PPV group. Thus, the results of the comparison of BCVA between STTA and PPV groups should be interpreted with caution.

On the other hand, no significant progression of cataract stages was observed after STTA injection in this study. Thus, the cataract formation may not be related to no significant improvement of visual acuity at 3 months or 6 months after STTA injection and the reduction of macular thickness seemed not to be paralleled to the improvement of BCVA in the STTA group. Further outcomes including retinal sensitivity may be required to assess visual function before and after DME treatment.

VEGF is one of the main factors involved in the development and the progression of DME. ${ }^{13}$ VEGF is upregulated in retinal cells because of inflammation, ischemia, and hyperglycemia in diabetic patients, and the upregulation causes an increase in vascular permeability in the retina. ${ }^{11,14}$ In addition, there is increasing evidence that inflammation induced by diabetic stress is involved in the pathogenesis of increased vascular permeability that may cause DME. ${ }^{15}$ In addition, an earlier study showed that steroids can upregulate the tight junction proteins, ZO-1, which occlude the endothelial cells under diabetic conditions and tighten the retinal blood barrier. ${ }^{16}$ Thus, IVTA ${ }^{3,17}$ and STTA $^{4,18}$ can be used to treat DME by suppressing inflammation and reducing VEGF expression in the retina. ${ }^{19-21}$

The major complications of IVTA are cataracts, IOP elevation and endophthalmitis. Hirano et al reported that IVTA led to higher elevations of IOP than STTA. ${ }^{22}$ According to the Japanese survey of TA for ocular diseases, endophthalmitis occurred in seven $(0.12 \%)$ of 5,665 eyes administered with IVTA, and seven ( $0.026 \%)$ of 26,819 eyes with PPV that used TA as an adjunct to separate posterior hyaloids from the retina. ${ }^{23}$ After STTA, however, the incidence of endophthalmitis was only $0.008 \%$ (one eye) of 12,344 eyes. ${ }^{23} \mathrm{~A}$ recent study indicates that the incident risk 
of endophthalmitis after intravitreal injection of anti-VEGF drugs was $0.025 \%$ in the United Kingdom. ${ }^{24}$ Usually, however, repeated injection of anti-VEGF drugs is required for the treatment of DME. ${ }^{6-9}$ Thus, the risk of post-intravitreal anti-VEGF endophthalmitis is significantly increased. In fact, the pooled analysis of the RESOLVE and RESTORE studies showed that an incidence rate of endophthalmitis was $1.4 \%$ at 1 year. ${ }^{6}$ In the study of the Diabetic Retinopathy Clinical Research Network, endophthalmitis occurred in one eye $(0.5 \%)$ of 187 participants in the ranibizumab prompt laser treatment group and two eyes (1\%) of 188 participants in the ranibizumab plus deferred laser treatment groups. $^{7}$ Taken together, STTA has a significantly lower risk of endophthalmitis than IVTA and intravitreal injection of anti-VEGF drugs.

Our study has a limitation because it was a retrospective study and the number of patients is small. In addition, the follow-up period of this study is not long. Thus, further randomized control studies with longer follow-up periods are needed to confirm the effectiveness of STTA compared to other treatments including PPV.

\section{Conclusion}

STTA and PPV significantly reduced CMT in patients with DME, and the differences in the BCVA and CMT between the two groups were not significant. Although the results of recent studies recommend combined therapies for the treatment of DME, STTA may be an alternative treatment for DME, especially when patients do not agree to undergo surgical treatments.

\section{Acknowledgments}

This study is supported by a Grant in Aid from the Ministry of Education, Science, Sports and Culture of the Japanese Government. We thank Professor Duco Hamasaki of the Bascom Palmer Eye Institute of the University of Miami for editing the manuscript.

\section{Author contributions}

$\mathrm{SN}$ conducted the data analysis and wrote the manuscript. All authors performed the STTA and/or PPV and were involved with the data collection. TO, and SY designed, wrote and edited the manuscript. All authors contributed toward data analysis, drafting and revising the paper and agree to be accountable for all aspects of the work.

\section{Disclosure}

The authors report no conflicts of interest in this work.

\section{References}

1. O'Doherty M, Dooley I, Hickey-Dwyer M. Interventions for diabetic macular oedema: a systematic review of the literature. Br JOphthalmol. 2008;92(12):1581-1590.

2. Photocoagulation for diabetic macular edema. Early Treatment Diabetic Retinopathy Study report number 1. Early Treatment Diabetic Retinopathy Study research group. Arch Ophthalmol. 1985; 103(12):1796-1806.

3. Ho TC, Lai WW. Intravitreal triamcinolone acetonide for diabetic macular edema. Ophthalmologica. 2006;220(5):349-350.

4. Ohguro N, Okada AA, Tano Y. Trans-Tenon's retrobulbar triamcinolone infusion for diffuse diabetic macular edema. Graefe's Arch Clin Exp Ophthalmol. 2004;242(5):444-445.

5. Takatsuna Y, Yamamoto S, Nakamura Y, Tatsumi T, Arai M, Mitamura Y. Long-term therapeutic efficacy of the subthreshold micropulse diode laser photocoagulation for diabetic macular edema. Jpn $J$ Ophthalmol. 2011;55(4):365-369.

6. Mitchell P, Bandello F, Schmidt-Erfurth U, et al. The RESTORE study: ranibizumab monotherapy or combined with laser versus laser monotherapy for diabetic macular edema. Ophthalmology. 2011;118(4):615-625.

7. Diabetic Retinopathy Clinical Research Network; Elman MJ, Qin H, Aiello LP, et al. Intravitreal ranibizumab for diabetic macular edema with prompt versus deferred laser treatment: three-year randomized trial results. Ophthalmology. 2012;119(11):2312-2318.

8. Sultan MB, Zhou D, Loftus J, Dombi T, Ice KS; Macugen 1013 Study Group. A phase 2/3, multicenter, randomized, double-masked, 2-year trial of pegaptanib sodium for the treatment of diabetic macular edema. Ophthalmology. 2011;118(6):1107-1118.

9. Do DV, Nguyen QD, Boyer D, et al. One-year outcomes of the da Vinci Study of VEGF Trap-Eye in eyes with diabetic macular edema. Ophthalmology. 2012;119(8):1658-1665.

10. Doi N, Sakamoto T, Sonoda Y, et al. Comparative study of vitrectomy versus intravitreous triamcinolone for diabetic macular edema on randomized paired-eyes. Graefe's Arch Clin Exp Ophthalmol. 2012;250(1):71-78.

11. Qi HP, Bi S, Wei SQ, Cui H, Zhao JB. Intravitreal Versus Subtenon Triamcinolone Acetonide Injection for Diabetic Macular Edema: A Systematic Review and Meta-analysis. Curr Eye Res. 2012; 37(12):1136-1147.

12. Hoerauf H, Brüggemann A, Muecke M, et al. Pars plana vitrectomy for diabetic macular edema. Internal limiting membrane delamination vs posterior hyaloid removal. A prospective randomized trial. Graefe's Arch Clin Exp Ophthalmol. 2011;249(7):997-1008.

13. Nguyen QD, Tatlipinar S, Shah SM, et al. Vascular endothelial growth factor is a critical stimulus for diabetic macular edema. Am J Ophthalmol. 2006;142(6):961-969.

14. Lang GE. Diabetic macular edema. Ophthalmologica. 2012;227(1): 21-29.

15. Kern TS. Contributions of Inflammatory Processes to the Development of the Early Stages of Diabetic Retinopathy. Exp Diabetes Res. 2007;2007:95103. doi:10.1155/2007/95103.

16. Felinski EA, Antonetti DA. Glucocorticoid regulation of endothelial cell tight junction gene expression: novel treatments for diabetic retinopathy. Curr Eye Res. 2005;30(11):949-957.

17. Gillies MC, Sutter FK, Simpson JM, Larsson J, Ali H, Zhu M. Intravitreal triamcinolone for refractory diabetic macular edema: two-year results of a double-masked, placebo-controlled, randomized clinical trial. Ophthalmology. 2006;113(9):1533-1538.

18. Wada M, Ogata N, Minamino K, Koriyama M, Higuchi A, Matsumura M. Trans-Tenon's retrobulbar injection of triamcinolone acetonide for diffuse macular edema. Jpn J Ophthalmol. 2005;49(6): 509-515.

19. Nauck M, Roth M, Tamm M, et al. Induction of vascular endothelial growth factor by platelet-activating factor and platelet-derived growth factor is downregulated by corticosteroids. Am J Resp Cell Mol Biol. 1997;16(4):398-406. 
20. Nauck M, Karakiulakis G, Perruchoud AP, Papakonstantinou E, Roth M. Corticosteroids inhibit the expression of the vascular endothelial growth factor gene in human vascular smooth muscle cells. Eur $J$ Pharmacol. 1998;341(2-3):309-315.

21. Sears JE, Hoppe G. Triamcinolone acetonide destabilizes VEGF mRNA in Muller Cells under continuous cobalt stimulation. Invest Ophthalmol Visual Sci. 2005;46(11):4336-4341.

22. Hirano Y, Ito T, Nozaki M, et al. Intraocular pressure elevation following triamcinolone acetonide administration as related to administration routes. Jpn J Ophthalmol. 2009;53(5):519-522.
23. Sakamoto T, Hida T, Tano Y, et al. [Survey of triamcinolone acetonide for ocular diseases in Japan]. Nihon Ganka Gakkai Zasshi. 2007;111(12):936-945. Japanese.

24. Lyall DA, Tey A, Foot B, et al. Post-intravitreal anti-VEGF endophthalmitis in the United Kingdom: incidence, features, risk factors, and outcomes. Eye (Lond). 2012;26(12):1517-1526.
Clinical Ophthalmology

\section{Publish your work in this journal}

Clinical Ophthalmology is an international, peer-reviewed journal covering all subspecialties within ophthalmology. Key topics include: Optometry; Visual science; Pharmacology and drug therapy in eye diseases; Basic Sciences; Primary and Secondary eye care; Patient Safety and Quality of Care Improvements. This journal is indexed on

\section{Dovepress}

PubMed Central and CAS, and is the official journal of The Society of Clinical Ophthalmology (SCO). The manuscript management system is completely online and includes a very quick and fair peer-review system, which is all easy to use. Visit http://www.dovepress.com/ testimonials.php to read real quotes from published authors. 